\title{
Self-Transcendent Aspirations and Life Satisfaction: The Moderated Mediation Role of Gratitude Considering Conditional Effects of Affective and Cognitive Empathy
}

\section{OPEN ACCESS}

Edited by:

Dario Paez,

University of the Basque Country,

Spain

Reviewed by:

Silvia Ubillos Landa, University of Burgos, Spain Jose Luis González-Castro, University of Burgos, Spain

Gonzalo Martínez-Zelaya,

Viña del Mar University, Chile

*Correspondence:

Xavier Orio

xavier.orio/@unab.cl

tORCID:

Xavier Orio

orcid.org/0000-0001-7130-7729

Jesús Unanue

orcid.org/0000-0002-3815-6567

Rafael Miranda

orcid.org/0000-0001-8640-6439

Alberto Amutio

orcid.org/0000-0003-3989-9992

Specialty section:

This article was submitted to Personality and Social Psychology,

a section of the journal

Frontiers in Psychology

Received: 29 April 2020

Accepted: 29 July 2020

Published: 25 August 2020

Citation:

Oriol X, Unanue J, Miranda $R$

Amutio A and Bazán C (2020)

Self-Transcendent Aspirations

and Life Satisfaction: The Moderated

Mediation Role of Gratitude

Considering Conditional Effects

of Affective and Cognitive Empathy.

Front. Psychol. 11:2105.

doi: 10.3389/fpsyg.2020.02105

\author{
Xavier Oriol ${ }^{1 * t}$, Jesús Unanue ${ }^{2 \dagger}$, Rafael Miranda ${ }^{3 \dagger}$, Alberto Amutio ${ }^{1 \dagger}$ and César Bazán ${ }^{4}$ \\ ${ }^{1}$ Faculty of Education and Social Science, Universidad Andrés Bello, Santiago, Chile, ${ }^{2}$ Programa de Doctorado en \\ Educación y Sociedad, Facultad de Educación y Ciencias Sociales, Universidad Andrés Bello, Santiago, Chile, ${ }^{3}$ Department \\ of Psychology, Universidad Continental, Lima, Peru, ${ }^{4}$ Faculty of Educación, Universidad Peruana de Ciencias Aplicadas, \\ Lima, Peru
}

Life aspirations are considered one of the most relevant components for human beings to give meaning and purpose to their existence. Different studies emphasized the relevance of intrinsic life aspirations to promote life satisfaction. However, few studies analyze the specific role of the intrinsic aspirations that have been recently categorized as self-transcendent. Self-transcendent aspirations are focused on helping others and improving society and, consequently, are considered aspirations whose purpose transcends oneself. In this sense, the objective of this study is to observe how selftranscendent aspirations are related to life satisfaction through dispositional gratitude. Additionally, we aim to study the moderating role of cognitive and affective empathy. There were 1,356 students (mean age $=21.5$, standard deviation $=2.35$ years) who took part in a scholarship program funded by the Education Ministry of Peru (PRONABEC), of which $57.7 \%$ were men and $42.3 \%$ were women. Results show a strong relationship between self-transcendent aspirations, gratitude, and cognitive and affective empathy. In the mediation analysis, an indirect effect of self-transcendent aspirations is observed on life satisfaction via gratitude. However, the moderated mediation showed that the addition of cognitive and affective empathy conditions the mediation effect. In this way, cognitive empathy has a significant interaction in the relationships between selftranscendent aspirations and gratitude, and between self-transcendent aspirations and life satisfaction. Results are discussed to emphasize the relevance of the mediating and moderating mechanisms considered in this study for the understanding of how self-transcendent life aspirations may promote life satisfaction.

Keywords: self-transcendent aspirations, gratitude, cognitive empathy, affective empathy, life satisfaction

\section{INTRODUCTION}

Life aspirations reflect long-term goals and are considered one of the most relevant components for human beings to give meaning and purpose to their existence (Steger et al., 2006). Aspirations enable prospective thinking (about the future) and allow us to direct our actions and organize our cognitive and affective processes in the present time (Seligman et al., 2013; Baumeister et al., 2016). 
According to the self-determination theory (SDT) proposed by Ryan and Deci (2000), life aspirations drive us and lead our choices and lifestyles. To measure these aspirations, Kasser and Ryan (1996) developed the Aspiration Index, a scale to assess intrinsic aspirations (personal growth, close relationships, community involvement, and physical health), as well as extrinsic aspirations (popularity, financial success, and image). Different studies show that intrinsic aspirations are associated with the "own nature" of the individual and therefore entail high probabilities of increasing well-being indicators such as positive affect and vitality (Lekes et al., 2010; Hope et al., 2016), whereas extrinsic aspirations are related to materialistic motives and have been linked to feelings of frustration and decreased life satisfaction (Dittmar et al., 2014; Unanue et al., 2014).

Grouzet et al. (2005) created a new classification of these life aspirations, which, besides the categories intrinsic and extrinsic, makes a distinction between self-transcendent and physical goals. According to these authors, self-transcendent goals are intrinsic aspirations that are considered prosocial, as they imply connecting with others and going beyond selfish concerns. More recently, Martela et al. (2019) conducted a study with two samples of adults to verify, using a circular stochastic modeling approach, if, in addition to the intrinsic and extrinsic categories, aspirations could also be categorized within the physical self vs. transcendence axes. The results confirmed that the relationship between aspirations can be described as a set of variables distributed along the circumference of a circle.

\section{Self-Transcendent Aspirations and Subjective Well-Being}

According to SDT, understanding the role played by life aspirations in subjective well-being (SWB) is fundamental (Kasser and Ryan, 1993; Bandura, 1997; Martela et al., 2019). Different studies have related intrinsic aspirations to different indicators of well-being (for review Ryan and Deci, 2017). However, few studies have linked these aspirations to the affective and cognitive components of SWB, as developed by Diener (1984). As such, SWB comprises a cognitive component, which is measured by asking people how satisfied they are with their lives (life satisfaction), and an affective component, which refers to the presence of positive affect or to the absence of negative affect, and it is assessed by inquiring about the experience of specific emotions during the previous day or week (Jebb et al., 2020).

Some of the research on the relationship between intrinsic aspirations and the affective and cognitive components of SWB shows a positive and significant relationship with positive affect (Kasser and Ryan, 1996; Romero et al., 2012; Martela et al., 2019). Also, a positive and significant relationship was found between intrinsic aspirations and life satisfaction in the studies by Romero et al. (2012) and Nishimura and Suzuki (2016); however, a negative and significant relationship was discovered in the work conducted by Allan and Duffy (2014). More recently, Martela et al. (2019) observed, by means of a regression analysis, that intrinsic aspirations have a positive and significant relationship with life satisfaction, but the significant effect disappeared when considering the participant's mean scores for life aspiration (calculated through the mean of the importance rated to the 13 intrinsic and extrinsic aspirations for each of the participants).

If we consider aspirations categorized by their axes, selftranscendence vs. physical self (Grouzet et al., 2005; Martela et al., 2019), and their relationship with the components of well-being, specifically, the intrinsic aspiration of community contribution (i.e., generativity and helping others), which is the closest to the self-transcendence axis (Martela et al., 2019), has been linked to both positive affect and life satisfaction, as well as to the global component of SWB (Martela and Ryan, 2016; Martela et al., 2019). Concretely, the items of this type of self-transcendent aspiration refer to the importance of objectives related to helping others and improving society and consequently are considered aspirations whose purpose transcends oneself.

In a recent review article published by Diener et al. (2018), the authors emphasize the importance of considering fundamental aspects like aspirations related to social connection with others as predictors in SWB measures. Much of the existing literature indicates that people's motivation to build and maintain social relationships is essential for survival and well-being (Leary and Baumeister, 2017). Additionally, when human beings provide support to others, this may give them a sense of meaning that is associated with positive affect and life satisfaction (Post, 2005; Siedlecki et al., 2014).

In conclusion, many of the previous studies based on SDT (Ryan and Deci, 2000) that relate to life aspirations have found that intrinsic aspirations are positively related to different wellbeing indicators. Furthermore, recently, interest in the study of intrinsic aspirations that promote self-transcendence and their relationship with the different components of SWB has grown (Grouzet et al., 2005; Martela et al., 2019). Specifically, this research work seeks to demonstrate the relationship between self-transcending life aspirations that represent long-term goals focused on helping the community and that transcend the self, and the cognitive component of well-being (i.e., life satisfaction), while considering different mechanisms that mediate and moderate this relationship. Setting long-term goals is essential for human beings, but progressing toward them is what contributes to increasing satisfaction with life (Diener, 1998). Therefore, we believe that a better understanding on this subject is necessary, because different mechanisms, such as gratitude and empathy, are fundamental to maintain long-lasting interpersonal connections and promote prosocial behavior, while at the same time they intervene in the relationship between self-transcendent aspirations and satisfaction with life.

\section{Gratitude as a Potential Mediator}

Over the past years, there has been increasing interest in the role of transcendence emotions such as gratitude in life satisfaction (Wood et al., 2008; Robustelli and Whisman, 2018). Gratitude falls within the categories of self-transcendent emotions (Van Cappellen et al., 2016; Stellar et al., 2017) and "other-praising emotions," according to the moral categories developed by Haidt (2003). This emotion is experienced when a person is helped by others. It is usually defined as a state or as a trait (Emmons and McCullough, 2004) and can act as a driver to enhance the welfare of others (Bartlett and DeSteno, 2006; Campos et al., 2013). 
Self-transcendent emotions such as gratitude are considered emotions that promote the development and maintenance of long-term social relationships (Stellar et al., 2017; DeSteno, 2018). Different studies have demonstrated that gratitude stimulates prosocial behavior toward others (for a review, see McCullough et al., 2001). Particularly, people who experience gratitude have more possibilities of helping strangers (Bartlett and DeSteno, 2006). In this sense, gratitude has been related to prosocial conducts and social support, which also promote life satisfaction (Algoe, 2012; Alkozei et al., 2018).

Additionally, gratitude is oriented toward noticing positive outcomes in life and promotes positive experiences and, specifically, positive emotions in daily life, which broaden the scope of thought and increase satisfaction with one's life (Emmons et al., 2019). So, when people feel constantly grateful for the situations happening and these are seen as a gift, they are more likely to increase their personal resources to face daily experiences in a more positive way (Unanue et al., 2019). Along the same line, the broaden-and-build theory developed by Fredrickson (2004) suggests that gratitude can broaden an individual's awareness of positivity and contribute to the accumulation of resources for achieving life goals, thus increasing life satisfaction.

Like other self-transcendent emotions such as awe and compassion, gratitude requires a personal view that transcends the own self to focus on others (Stellar et al., 2017). The elicitation of this type of emotions, as it occurs with other emotions, depends on the relevance that social and cultural contexts attribute to self-focused concerns (Mesquita et al., 2016). In a recent study, De Leersnyder et al. (2018) observed significant differences in the emotional experience of self-focused and otherfocused concerns. Consequently, it is important to explore how these long-term life aspirations can promote emotions such as gratitude and how gratitude, in turn, can facilitate other-oriented motivation. So, the first goal of this study was to observe how selftranscendent aspirations are related to life satisfaction through dispositional gratitude. Taking into account the aforementioned, we hypothesize that:

H1. Self-transcendent aspirations will be positively related to life satisfaction through gratitude.

Specifically, we expect that gratitude (i.e., directing cooperation to others and fostering long-term relationships) will mediate the relationship between self-transcendent aspirations and life satisfaction.

\section{The Moderation Role of Cognitive and Affective Empathy}

Empathy is considered a complex affective and cognitive process of understanding and feeling others' emotions (Baron-Cohen and Wheelwright, 2004; Jolliffe and Farrington, 2006). Empathy is a primary mechanism fundamental for interpersonal connection and therefore acts as a prosocial behavior driver through sensitivity to emotional signals from others (for review, see Eisenberg, 2010; De Waal, 2012).
Different studies have associated the lack of empathy with violence, aggression, and other interpersonal problems (Blair et al., 2005; Mitsopoulou and Giovazolias, 2015), whereas empathy has been linked to positive interpersonal relationships and friendship (Durlak et al., 2011; Hayes and Ciarrochi, 2015). Nevertheless, other studies have hardly found a weak relationship between empathy and aggressiveness (for a review, see Vachon et al., 2014).

An important aspect of empathy seems to be that the focus of concern has to be others in order to prevent excessive personal anguish (Eisenberg et al., 1996). Previous studies have shown that being empathetic with others is related to a tendency to prosocial behavior, social closeness, and life satisfaction (Morelli et al., 2015). However, occasionally, in the absence of the cognitive mechanisms conducive to perspective-taking, an excess of affective empathy can cause personal distress and suffering (Eisenberg et al., 2006; Blanco-Donoso et al., 2017; Amutio et al., 2018) and lead to a decrease in prosociality (Decety and Lamm, 2009; Decety and Yoder, 2016). This fact has sparked a debate on how to separate the mechanisms of affective and cognitive empathy (Cuff et al., 2016).

Both mechanisms (affective and cognitive) have been speculated to be relevant to life satisfaction. However, difficulties for perspective-taking when facing affective stimuli can cause increased negative affect, including distress and clinical symptomatology (Morelli et al., 2015; Lachmann et al., 2018). More generally, people who experience difficulties to assess and cope with a stressful situation feel anguished, and this impairs their prosocial qualities, including empathy (Batson, 1991). Following this perspective, different studies have pointed to the need of understanding that empathy is a general term to describe several forms in which people respond to one another, including sharing and thinking about the feeling of others (for a review, see Zaki, 2020). This implies that empathy can encourage ways of worrying about and experiencing the same emotions as others, but without mechanisms that target cognitively and rationally perspective-taking, suffering and emotional wear may occur (Bloom, 2017a,b). In this sense, the definition of cognitive empathy (perspective-taking) implies a more rational processing that promotes sensitivity to justice for others, as well as the endorsement of moral rules, which is also the case with emotions such as compassion (Decety and Yoder, 2016; Bloom, 2017b).

Aspirations that imply life goals can generate frustration in people if they are not encompassed by achievements or materialization (Ryan and Deci, 2000). Therefore, in the case of self-transcendent aspirations, as already noted, the experience of dispositional gratitude is considered a fundamental mediating mechanism for relating these aspirations to life satisfaction, thus preventing them to cause frustration. Nevertheless, promoting gratitude implies building reciprocal constant relationships in terms of self-benefit and benefactorcost (Emmons and McCullough, 2004; Van Cappellen et al., 2016). In addition, human beings have neural mechanisms, such as empathy and mentalization, which enable the simulation of others' mental states, which gives rise to gratitude and reciprocity ( $\mathrm{Yu}$ et al., 2018). In this sense, the literature 
on this subject leads us to think that high and low scores for both forms of empathy can condition the relationship between aspirations and the constant experience of gratitude. Without high empathy, attributing generous intentions to others is difficult, and this, in turn, affects the experience of gratitude (Bloom, 2017b; Stern et al., 2019). Furthermore, as suggested by the literature, the experience of affective empathy can take a high toll in people (Zaki, 2020), generating more distress and suffering and consequently impairing the experience of gratitude.

In the same line, we also want to demonstrate how both forms of empathy moderate the relationship between self-aspirations and life satisfaction. From an evolutional perspective, empathy promotes the connection between people (Bloom, 2017a), which we believe is fundamental to achieve high levels of SWB in the search of goals that transcend self-related concerns to common good. Without a high ability to understand other people's thoughts and feelings, it would be hard for people to experience a feeling of well-being in their connection with others or prosocial and altruistic behaviors toward others (Grühn et al., 2008). Additionally, as already mentioned, the differences in the experience of affective and cognitive empathy in the wellbeing perception (Bloom, 2017b; Zaki, 2020) lead us to think that both forms of empathy can condition the relationship between aspirations and life satisfaction differently. In this sense, it is expected that both forms of empathy will show a moderating effect in the relationship between aspirations and gratitude, and in the relationship between aspirations and life satisfaction. Therefore, the following hypotheses are also formulated (Figure 1):

H2. Cognitive and affective empathy are expected to have a moderating effect on the relationship between selftranscendent aspirations and gratitude. Specifically, all interactions will be significant.

H3. Both forms of empathy are expected to condition the relationship between self-transcendent aspirations and life satisfaction through gratitude. Therefore, significant moderated mediation indexes are expected for the conditioned effects, considering both forms of empathy.

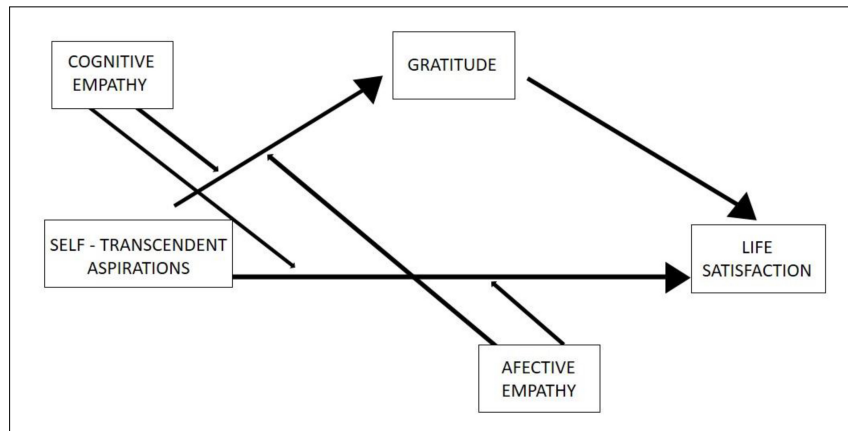

FIGURE 1 | Conceptual model: moderated mediation between self-transcendent aspirations and life satisfaction.

\section{MATERIALS AND METHODS}

\section{Participants}

The sample is composed of 1,356 university students [mean age $=21.5$, standard deviation $(S D)=2.35$ years], of which $57.7 \%$ are men and $42.3 \%$ women. All of them are part of a total of 40,000 students who belong to a scholarship program financed by the Education Ministry of Peru (PRONABEC). The Ministry of Education conducted this study to verify the indicators related to well-being in university students from this program. In order to obtain an adequate psychometric validation of the global questionnaire (78 items), 1,400 students were randomly selected to participate in the study, of which 1,356 were successfully completed.

A sensitivity power analysis was conducted using G*Power 3.1 (Faul et al., 2009) considering $\alpha=0.05$, a desired power of 0.80 , and 11 parameters in a moderate mediation model with two linear regressions, each of which had three principal predictors and two interactions. An effect size of $f^{2}=0.006$ was obtained. Thus, the model with $80 \%$ power can detect a predictor with a population effect size of $f^{2}=0.006$, which is considered a small size by Cohen (1992). The study had the support of an external group of university researchers that helped create the questionnaire and provided insights into the ethical aspects below.

\section{Procedure}

The research team and the Ministry of Education developed the questionnaire, paying special attention to compliance with the ethical standards required for this type of study. To this end, informed consents that explained the objectives, confidentiality, and the voluntary character of the study were created to be signed by participants prior to survey application. Different specialists from the same unit established the protocols for the implementation of the survey. The Research Ethics Committee of the Continental University (Peru) reviewed and approved the ethical suitability of the study considering the ethical recommendations of the Declaration of Helsinki for studies on human beings.

PRONABEC has a virtual platform in INTRANET (private network system), which is a communication system that allows for sending and collecting information from its students. Through this system, the PRONABEC team programmed the online application of the survey. The questionnaire was sent to a randomized sample of students from the program. When the questionnaire was launched on the platform, all selected students received a notification via email so that they could access and complete the survey.

Before filling in the questionnaire, students had to read the research purpose and provide an electronic signature. Students took an average of 30 to $40 \mathrm{~min}$ to complete the questionnaire. It is worth mentioning that this survey was available for 2 weeks on the platform with the aim of collecting as much information as possible. 


\section{Measures}

\section{Self-Transcendent Aspirations}

The subscale "community involvement" from the Aspirations Index developed by Kasser and Ryan (1996) was used. This subscale asks respondents how important some aspirations related to prosociality are to them (e.g., "To help others improve their lives;" "To help people in need") in a 1- to 7-point scale ("very important"). For this study, the scale presents a Cronbach $\alpha$ of 0.91 .

\section{Gratitude}

The subscale of gratitude from the Positive Emotion Questionnaire developed by Oros (2014) was used. This questionnaire assesses different dispositional emotions such as gratitude, sympathy, serenity, and satisfaction. The gratitude subscale contains four items related to gratitude experiences in daily life. To answer the questionnaire, students need to answer to which extent they agree or disagree with the statements in a range from 1 (totally disagree) to 5 (totally agree) (e.g., "I am thankful for the things I have;" "I like to be thankful with other people"). Cronbach $\alpha$ for this scale was 0.91 .

\section{Cognitive and Affective Empathy}

The 9-item scale proposed by Soto and Muchotrigo (2015) was used to assess empathy. This measure evaluates the construct for the affective (e.g., "I get sad when I see people crying") and cognitive dimensions (e.g., "When someone is depressed I use to understand him/her) in a range between 1 (totally disagree) and 5 (totally agree). Cronbach $\alpha$ was 0.86

\section{Life Satisfaction}

The Brief Multidimensional Students' Life Satisfaction Scale developed by Seligson et al. (2003) was used. This scale contains five items that deal with different domains related to life satisfaction. The items measure to what extent the students feel "dissatisfied" or "satisfied" with the following aspects of their life: (1) family life, (2) friendships, (3) life at school/institute, (4) selfsatisfaction, and (5) the place where they live. This instrument uses a scale from 1 "very dissatisfied" to 7 "very satisfied." Cronbach $\alpha$ was 0.90 .

\section{Data Analysis}

Descriptive analyses were conducted using SPSS 23.0. For mediation and moderate mediation analyses, the models 4 and 10 of the macro Process 3.2.01 proposed by Preacher and Hayes (2008) for SPSS were used, respectively. Mediation indirect effects between the hypothesized variables were computed. Results will reflect statistically significant indirect effects by testing the confidence interval (CI) derived from 10,000 bootstrap repetitions at $95 \%$ to verify the mediation effect. The indirect effect is significant if the CI does not contain the value zero (Hayes, 2017). Similarly, a moderate mediation analysis between the hypothesis variables was carried out, evaluating the indexes of partial moderated mediation. These indices "quantify the rate of change in the indirect effect of independent variables as one moderator changes but the other is held constant" (Hayes, 2018, p. 11), which will show a statistically significant indirect effect if the CI does not contain the value zero (Hayes, 2018). It must be noted that the estimation of the parameters for each model was carried out by means of ordinary least squares regression. Finally, we ruled out the gender and age control variables because they are not significantly correlated with life satisfaction.

\section{RESULTS}

\section{Descriptive Statistics}

First, means, SDs, and bivariate correlations between all the variables are presented using SPSS 23.0 (Table 1). High, positive, and significant correlations can be observed across all the variables above, with gratitude and cognitive empathy standing out $(r=0.56, p=0.000)$.

\section{Mediation Analysis}

The results of the first model (Figure 2), with dispositional gratitude as a possible mediating variable, self-transcendent aspirations as an independent or predictor variable, and life satisfaction as a dependent variable, show that self-transcendent aspirations have an direct effect that is not statistically significant on life satisfaction $(\beta=0.03, p>0.05)$. However, when introducing gratitude, we observe that it has a statistically significant indirect effect $(\beta=0.16,95 \% \mathrm{CI}=0.107-0.205)$. Thus, the relationship between self-transcendent aspirations and life satisfaction is interpreted as being mediated by dispositional gratitude. Values of $R^{2}$ fluctuated from 0.27 to $0.36(p=0.000)$.

\section{Moderate Mediation Analysis}

For the second model (Figure 1), taking self-transcendent aspirations as the independent variable, keeping life satisfaction as the dependent variable, and gratitude as a mediator, cognitive empathy and affective empathy are introduced as possible moderators of this mediation.

For the model that takes gratitude as dependent variable (Table 2), the construct was positively and significantly predicted by self-transcendent aspirations $(\beta=0.47, p<0.001)$ and cognitive empathy $(\beta=0.77, p<0.001)$, whereas it was negatively and significantly affected by the interaction between self-transcendent aspirations and cognitive empathy $(\beta=-0.08$, $p<0.01)$. However, affective empathy predicts gratitude positively but not significantly $(\beta=0.08, p>0.05)$, and the same is true for the interaction with self-transcendent aspirations $(\beta=-0.02, p>0.05)$. Direct conditional effects are shown in Table 2 for the case where both moderators assume values of $-1 S D$, mean, and $+1 S D$ and their combinations. The effects are significant at all levels.

Figure 3 shows the interaction between self-transcendent aspirations and cognitive empathy over gratitude. Students with low self-transcendent aspirations and low cognitive empathy present significant differences in gratitude compared to those with low self-transcendent aspirations and high cognitive empathy. However, the difference is smaller between students with high self-transcendent aspirations and low cognitive empathy, and students with high self-transcendent aspirations and high cognitive empathy. The slope in the case of low cognitive 
TABLE 1 | Means, standardized deviations, and correlations between all variables.

\begin{tabular}{|c|c|c|c|c|c|c|c|c|c|c|}
\hline & & Mean & $S D$ & 1 & 2 & 3 & 4 & 5 & 6 & 7 \\
\hline 1. & Gender & 1.42 & 0.49 & & & & & & & \\
\hline 2. & Age & 21.53 & 2.35 & $-0.21^{\star \star}$ & & & & & & \\
\hline 3. & Gratitude & 3.37 & 0.62 & $0.07^{\star \star}$ & 0.02 & & & & & \\
\hline 4. & ST aspirations & 5.16 & 0.91 & $0.13^{\star \star}$ & 0.01 & $0.52^{\star \star}$ & & & & \\
\hline 5. & Affect empathy & 2.44 & 0.90 & $0.06^{\star}$ & 0.04 & $0.26^{\star \star}$ & $0.16^{\star \star}$ & & & \\
\hline 6. & Cognitive empathy & 2.90 & 0.66 & 0.04 & 0.01 & $0.56^{\star \star}$ & $0.40^{\star \star}$ & $0.53^{\star \star}$ & & \\
\hline 7. & Life satisfaction & 4.69 & 1.42 & -0.01 & 0.01 & $0.32^{\star \star}$ & $0.19^{\star \star}$ & $0.08^{\star \star}$ & $0.20^{\star \star}$ & \\
\hline
\end{tabular}

${ }^{*} p<0.05,{ }^{* *} p<0.01$.

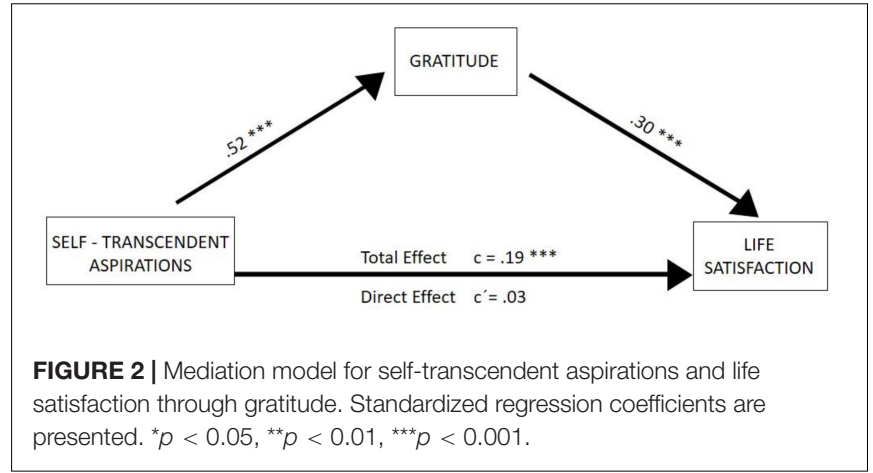

empathy is also slightly steeper than the slope of high cognitive empathy, but a higher level of dispositional gratitude is observed in both cases for high levels of the self-transcendent aspirations.

The results of the model with life satisfaction as a dependent variable show that affective empathy does not significantly influence life satisfaction $(\beta=0.06, p>0.05)$, but again selftranscendent aspirations are observed to have a positive and statistically significant effect $(\beta=0.63, p<0.005)$, as well as gratitude ( $\beta=0.56, p<0.001)$ and cognitive empathy $(\beta=1.18$, $p<0.005)$. With respect to the interactions in this model, only cognitive empathy and self-transcendent aspirations present a negative and significant effect on life satisfaction $(\beta=-0.21$, $p<0.005)$. Direct conditional effects are shown in Table 3. For the case in which both moderators assume values of $-1 S D$, mean, and $+1 S D$ and their combinations, only three out of nine effects are significant: $-1 \mathrm{SD}$ cognitive empathy and $-1 S D$ affect empathy $(\beta=0.12,95 \% \mathrm{CI}=0.11-0.23),+1 S D$ cognitive empathy and mean affect empathy $(\beta=-0.18,95 \% \mathrm{CI}=-0.32$ $0.03)$, and $+1 S D$ cognitive empathy and $+1 S D$ affect empathy $(\beta=-0.20,95 \% \mathrm{CI}=-0.31$ to -0.07$)$.

Figure 4 shows the effect of self-transcendent aspirations and cognitive empathy over life satisfaction, with participants who report higher levels of cognitive empathy and self-transcendent aspirations having

TABLE 2 | Conditional direct effects between self-transcendent aspirations and gratitude moderated by affect and cognitive empathy.

\begin{tabular}{|c|c|c|c|c|}
\hline Predictor & $\beta$ & SE & $\begin{array}{c}\text { Lower } 95 \% \\
\text { BootLLCI }\end{array}$ & $\begin{array}{c}\text { Upper } 95 \% \\
\text { BootULCI }\end{array}$ \\
\hline \multicolumn{5}{|l|}{ DV = gratitude as dependent variable model } \\
\hline Cognitive empathy & $0.77^{\star}$ & 0.1300 & 0.52 & 1.02 \\
\hline Self-transcendent aspirations $\times$ cognitive empathy & $-0.08^{\star \star}$ & 0.02 & -0.12 & -0.03 \\
\hline Affect empathy & 0.08 & 0.13 & -0.17 & -0.33 \\
\hline \multicolumn{5}{|c|}{ Conditional direct effect at different values of the moderator } \\
\hline Moderator values & $\beta$ & BootSE & BootLLCI & BootULCI \\
\hline$-1 S D$ cognitive empathy and $-1 S D$ affect empathy & $0.27^{\star}$ & 0.02 & 0.23 & 0.30 \\
\hline$-1 S D$ cognitive empathy and mean affect empathy & $0.25^{\star}$ & 0.02 & 0.21 & 0.29 \\
\hline$+1 S D$ cognitive empathy and $-1 S D$ affect empathy & $0.17^{*}$ & 0.04 & 0.09 & 0.25 \\
\hline$+1 S D$ cognitive empathy and mean affect empathy & $0.15^{\star}$ & 0.03 & 1.0 & 0.20 \\
\hline$+1 S D$ cognitive empathy and $+1 S D$ affect empathy & $0.13^{*}$ & 0.02 & 0.09 & 0.17 \\
\hline
\end{tabular}

${ }^{*} p<0.001,{ }^{* *} p<0.01$. 


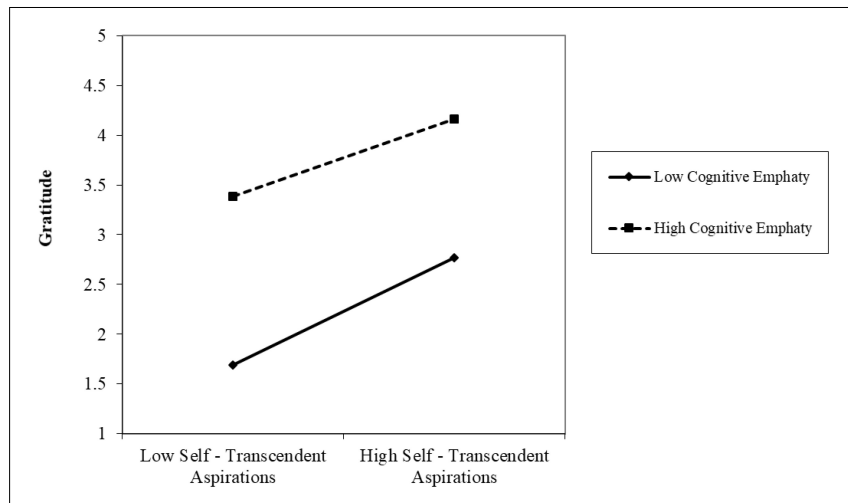

FIGURE 3 | Interaction between self-transcendent aspirations and cognitive empathy over gratitude.

increased levels of life satisfaction. Moreover, as selftranscendent aspirations increases, so does life satisfaction, regardless of the level of cognitive empathy. However, the regression slope is steeper for people with lower cognitive empathy.

Conditional indirect effects are presented in Table 4. In all cases, they are statistically significant. The index of partial moderated mediation was only significant for cognitive empathy ( $\beta=-0.04,95 \% \mathrm{CI}=-0.08$ to -0.01$)$. Therefore, only cognitive empathy moderates the mediating role of gratitude in the effect of self-transcendent aspirations on life satisfaction. Values of $R^{2}$ fluctuated from 0.13 to $0.44(p=0.000)$.

\section{DISCUSSION}

Aspirations and expectations for the future imply a type of prospective thinking relevant to the human being, which makes our species different from animals (Baumeister et al., 2016). This study aims to delve into how self-transcendent aspirations can affect the perception of our own life as a whole. Descriptive data obtained in this study show a positive relationship between selftranscendent aspirations and life satisfaction, as well as between aspirations and variables closer to prosociality, such as both forms of empathy and gratitude.

Following our first hypothesis, an indirect effect of selftranscendent aspirations is observed on life satisfaction through gratitude, thus confirming this hypothesis. Specifically, this mediating effect is total. Additionally, it must be noted that selftranscendent aspirations have a positive and significant direct effect on gratitude. This result underscores the relevance of this type of aspirations, which represent long-term goals that can drive emotions that strengthen and maintain interpersonal relationships in the long term such as gratitude (Stellar et al., 2017). Self-transcendent aspirations as community involvement focus people's interest not only on themselves, but also on others (Kasser and Ryan, 1996), and in this aspect, our results support the hypothesis that these aspirations are important to guide affective positive experiences induced by gratitude in daily life. Moreover, dispositional gratitude, which is considered a general tendency to respond to others with gratitude or appreciation (McCullough et al., 2002), can be an important mechanism for linking these aspirations to the subjective perception of well-being (i.e., life satisfaction). From a bottom-up perspective,

TABLE 3 | Conditional direct effects between self-transcendent aspirations and life satisfaction moderated by affect and cognitive empathy.

\begin{tabular}{|c|c|c|c|c|}
\hline Predictor & $\beta$ & SE & $\begin{array}{c}\text { Lower 95\% } \\
\text { BootLLCI }\end{array}$ & $\begin{array}{c}\text { Upper } 95 \% \\
\text { BootULCI }\end{array}$ \\
\hline \multicolumn{5}{|l|}{ DV = LS as dependent variable model } \\
\hline Self-transcendent aspirations & $0.63^{*}$ & 0.11 & 0.42 & 0.84 \\
\hline Gratitude & $0.56^{\star}$ & 0.08 & 0.41 & 0.71 \\
\hline Cognitive empathy & $1.18^{\star \star}$ & 0.37 & 0.46 & 1.90 \\
\hline Self-transcendent aspirations $\times$ cognitive empathy & $-0.21^{\star *}$ & 0.07 & -0.34 & -0.01 \\
\hline Affective empathy & 0.06 & 0.36 & -0.65 & 0.76 \\
\hline Self-transcendent aspirations $\times$ affective empathy & -0.02 & 0.07 & -0.15 & 0.11 \\
\hline
\end{tabular}

Conditional direct effect at different values of the moderator

\begin{tabular}{|c|c|c|c|c|}
\hline Moderator values & $\beta$ & BootSE & BootLLCI & BootULCI \\
\hline$-1 S D$ cognitive empathy and $-1 S D$ affective empathy & $0.12^{\star \star \star}$ & 0.06 & 0.01 & 0.23 \\
\hline$-1 S D$ cognitive empathy and mean affect empathy & 0.10 & 0.06 & -0.01 & 0.21 \\
\hline-1 SD cognitive empathy and $+1 S D$ affect empathy & 0.08 & 0.10 & -0.12 & 0.28 \\
\hline Mean cognitive empathy and $-1 S D$ affect empathy & -0.02 & 0.08 & -0.18 & 0.15 \\
\hline Mean cognitive empathy and mean affect empathy & -0.04 & 0.05 & -0.13 & 0.06 \\
\hline Mean cognitive empathy and $+1 S D$ affect empathy & -0.06 & 0.07 & -0.20 & 0.08 \\
\hline$+1 S D$ cognitive empathy and $-1 S D$ affect empathy & -0.16 & 0.12 & -0.39 & 0.08 \\
\hline$+1 S D$ cognitive empathy and mean affect empathy & $-0.18^{\star \star \star}$ & 0.08 & -0.32 & -0.03 \\
\hline$+1 S D$ cognitive empathy and $+1 S D$ affect empathy & $-0.20^{\star \star}$ & 0.06 & -0.32 & -0.07 \\
\hline
\end{tabular}

${ }^{*} p<0.001,{ }^{* *} p<0.01,{ }^{* * *} p<0.05$. 


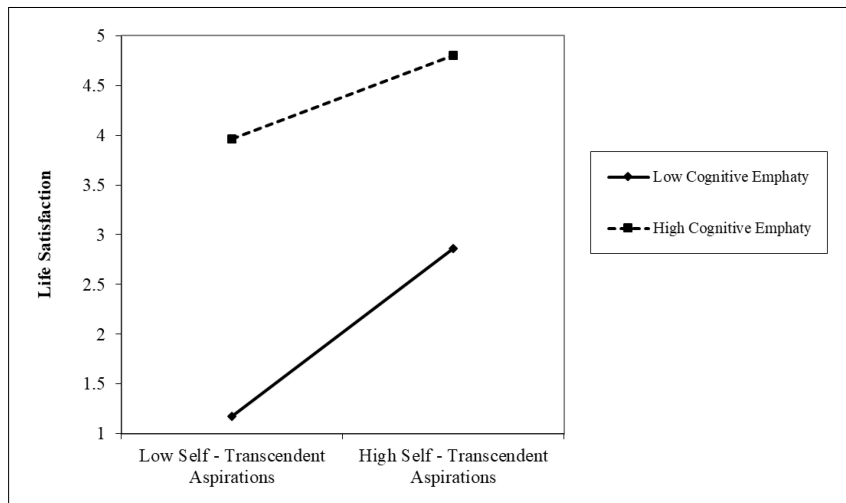

FIGURE 4 | Interaction between self-transcendent aspirations and cognitive empathy over life satisfaction.

positive and negative daily-life affective experiences contribute to build the cognitive judgment. that people make about their lives as a whole (Kahneman and Riis, 2005). Consequently, the tendency to experience gratitude can promote the accumulation of positive affective experiences that increase life satisfaction. As suggested by Diener (1998) for the well-being of human beings, it is important not only to set long-term goals, but also to achieve them. In this sense, dispositional gratitude, as indicated by our results, may encourage the materialization of self-transcendent aspirations into gratifying actions in daily life that promote the accumulation of positive personal resources, as well as keeping positive interpersonal relationships in the long term, which in turn increases life satisfaction.

Regarding the second hypothesis, high empathy and low cognitive empathy moderate the relationship between selftranscendence aspirations and gratitude. People who score higher in cognitive empathy experience more gratitude than those with lower empathy. Nevertheless, the effect of the interaction is stronger in people with low scores in cognitive empathy than in people with high scores, which implies that this factor has an important effect on the relationship between self-transcendent aspirations and gratitude. These data support the importance of understanding others' affect for the development of emotions that fall into the category of prosocial emotions and or transcendence emotions (Stellar et al., 2017). In this sense, the development of cognitive empathy seems vital to promote emotions such as gratitude, which are basic to foster prosocial behavior (for review, see Ma et al., 2017). In another vein, affective empathy does not show a moderating effect, which may indicate, as observed in the literature, that cognitive perspective-taking toward others in empathy processes is essential to prevent the anxiety and other types of negative emotions that hinder gratitude (Decety and Lamm, 2009; Decety and Yoder, 2016). So, the second hypothesis is partially confirmed.

In the third hypothesis, we sought to confirm the moderating role of both forms of empathy in the relationship between aspirations and life satisfaction through gratitude. First, a significant interaction of cognitive empathy is observed, but without a moderating effect of affective empathy on the relationship between aspirations and life satisfaction. People with higher cognitive empathy present a positive significant relationship between self-transcendent aspirations and life satisfaction, and a significant effect is observed again on the interaction with people who have lower cognitive empathy. Consequently, the results confirm that, in the relationship with life satisfaction, low empathy also has a negative impact on the association between aspirations and the cognitive component of SWB.

Regarding the moderated mediation, a conditional indirect effect is observed, which takes place when considering both forms of empathy between aspirations and life satisfaction through gratitude. Nevertheless, as commented above, only the moderated mediation index for cognitive empathy is significant. Thus, the third hypothesis is partially confirmed. This underscores the relevance of considering the affective and cognitive mechanisms of empathy separately, as well as the possible role of cognitive

TABLE 4 | Conditional indirect effects between self-transcendent aspirations and life satisfaction through gratitude and moderated effects of affective and cognitive empathy.

BootSE

$\begin{array}{ll}0.15^{\star} & 0.02 \\ 0.14^{\star} & 0.02 \\ 0.13^{\star} & 0.03 \\ 0.12^{\star} & 0.03 \\ 0.11^{\star} & 0.02 \\ 0.10^{\star} & 0.02 \\ 0.09^{\star} & 0.03 \\ 0.08^{\star} & 0.02 \\ 0.07^{\star} & 0.02 \\ -0.04^{\star} & 0.02 \\ -0.01 & 0.02\end{array}$

\section{Lower $95 \%$}

BootLLCI

$\begin{array}{cc}0.10 & 0.19 \\ 0.10 & 0.18 \\ 0.08 & 0.19 \\ 0.07 & 0.17 \\ 0.08 & 0.15 \\ 0.06 & 0.14 \\ 0.04 & 0.15 \\ 0.05 & 0.12 \\ 0.05 & 0.11 \\ -0.08 & -0.01 \\ -0.04 & 0.02\end{array}$

\section{Moderator values}

$-1 S D$ cognitive empathy and $-1 S D$ affect empathy

$-1 S D$ cognitive empathy and mean affect empathy

$-1 S D$ cognitive empathy and $+1 S D$ affect empathy

Mean cognitive empathy and $-1 S D$ affect empathy

Mean cognitive empathy and mean affect empathy

Mean cognitive empathy and $+1 S D$ affect empathy

$+1 S D$ cognitive empathy and $-1 S D$ affect empathy

$+1 S D$ cognitive empathy and mean affect empathy

$+1 S D$ cognitive empathy and $+1 S D$ affect empathy

Index of partial moderated mediation for cognitive empathy

Index of partial moderated mediation for affect empathy

${ }^{*} p<0.05$. 
empathy in the promotion of life satisfaction and in the prevention of emotional exhaustion.

These results are in agreement with different studies focused on the effects of mindfulness meditation, which indicate that taking perspective of how oneself and others feel in a particular situation is essential to foster interest toward others and, at the same time, protect our own SWB (e.g., Dahl et al., 2015; Van Doesum et al., 2018). Other studies also indicate that affective empathy can increase the levels of stress and anxiety in the long term if it does not lead to a more cognitive perspective (Bloom, 2017b; Blanco-Donoso et al., 2017; Amutio et al., 2018).

As main limitations of this study, data presented are cross-sectional, and thus, it would be relevant to obtain longitudinal data to better define the causality relationships between the variables and consequently determine the effect of mediators on such relationships with more accuracy. Additionally, the inclusion of both components of SWB is also an important element to consider in future studies. As for self-transcendent aspirations, studies considering the self-transcendent vs. physical goals axis are still scarce.

One of the strengths of our article is its large sample size, which allows for detecting effect sizes as small as $f^{2}=0.006$, which helps minimize type II errors. However, a note of warning should be made. Because of our large sample size and its high power, it is very likely that almost all standardized paths in our models become significant irrespective of its strength. Indeed, our paths range from 0.02 (small) to 0.77 (strong), according to Richard et al. (2003). Therefore, "significance" is important, but readers are also encouraged to pay attention to the strength of each path.

\section{CONCLUSION}

First, our results show that self-transcendent life aspirations are strongly related to life satisfaction. This is relevant because of the following reasons: (i) currently, there is great interest in the relevance of prospective thinking for human beings, understanding that it is a motivational driver crucial to guide cognitive and affective processes (Forgas and Baumeister, 2018); (ii) over the last years, there has been growing interest in classifying intrinsic aspirations considering the categories physical vs. self-transcendent proposed by Grouzet et al. (2005). However, few studies have explored the relationship between selftranscendent aspirations, such as community contribution, and life satisfaction.

Although aspirations such as long-term goals can be relevant for the human being, the results show the interplay between different mechanisms for elucidating how aspirations focused on self-transcendence can increase life satisfaction. In this sense, selftranscendent aspirations promote the experience of gratitude, which, in turn, has a total mediating effect over life satisfaction. Thus, gratitude, as a trait emotion, plays a key role in the satisfaction that people experience with social relationships and contributes to the experience of positive affect in daily life, as well as nurturing personal resources (Fredrickson, 2004).

Another fundamental aspect is the role of empathy in these relationships and, specifically, in people with high levels of selftranscendent aspirations and high cognitive empathy. However, no moderating role is observed in the case of affective empathy. This confirms the relevance of a more rational perspective-taking for an increase of SWB.

From the perspective of developmental psychology, our results emphasize the importance of life aspirations focused on community well-being at schools. Understanding and internalizing the relevance of these long-term self-transcendent goals can encourage prosocial behavior in children and adolescents by means of emotions such as gratitude, as well as contribute to their life satisfaction.

\section{DATA AVAILABILITY STATEMENT}

The raw data supporting the conclusions of this article will be made available by the authors, without undue reservation, to any qualified researcher.

\section{ETHICS STATEMENT}

The studies involving human participants were reviewed and approved by the Comité de Ética en la Investigación de las Facultades de Humanidades y de Derecho de la Universidad Continental. The patients/participants provided their written informed consent to participate in this study.

\section{AUTHOR CONTRIBUTIONS}

XO developed the original idea and design of the research. RM contributed to the collection of the information. XO and JU wrote the article concerned with the writing and interpretation of results. JU, RM, and AA analyzed the data. AA and CB were in charge of the review. All authors read, reviewed, and approved the final manuscript.

\section{ACKNOWLEDGMENTS}

We would like to thank the Education Ministry of Peru (PRONABEC), for access to data of this study. We also like to thank to the Consolidated Research group - Grant Reference name: Culture, Cognition and Emotion. University of the Basque Country (UPV/EHU) and Basque Govern (Grant No. Ref IT1187-19); and the Ministry of Education - Grant Reference name: Culture, Coping and Emotional Regulation: Life and Collective Gatherings Grant No. PSI2017-84145-P. 


\section{REFERENCES}

Algoe, S. B. (2012). Find, remind, and bind: the functions of gratitude in everyday relationships. Soc. Pers. Psychol. Comp. 6, 455-469. doi: 10.1111/j.1751-9004. 2012.00439.x

Alkozei, A., Smith, R., and Killgore, W. D. (2018). Gratitude and subjective wellbeing: a proposal of two causal frameworks. J. Happiness Stud. 19, 15191542. doi: 10.1007/s10902-017-9870-1

Allan, B. A., and Duffy, R. D. (2014). Calling, goals, and life satisfaction: a moderated mediation model. J. Career Assess. 22, 451-464. doi: 10.1177/ 1069072713498574

Amutio, A., Pizarro, J. J., Basabe, N., Telletxea, S., and Harizmendi, M. (2018). Propiedades psicométricas de la Escala de Compasión hacia los Demás. Revist. Latinoamericana Psicol. Positiv. 04, 24-37.

Bandura, A. (1997). Self-Efficacy: The Exercise of Control. London: Macmillan.

Baron-Cohen, S., and Wheelwright, S. (2004). The empathy quotient: an investigation of adults with Asperger syndrome or high functioning autism, and normal sex differences. J. Autism Dev. Disord. 34, 163-175. doi: 10.1023/B: JADD.0000022607.19833.00

Bartlett, M., and DeSteno, D. (2006). Gratitude and prosocial behavior. Helping when it costs you. Psychol. Sci. 17, 319-325. doi: 10.1111/j.1467-9280.2006. 01705.x

Batson, C. D. (1991). The Altruism Question: Toward a Social Psychological Answer. Hillsdale, NJ: Erlbaum.

Baumeister, R. F., Oettingen, G., and Vohs, K. D. (2016). Pragmatic prospection: how and why people think about the future. Rev. Gen. Psychol. 20, 3-16. doi: 10.1037/gpr0000060

Blair, J., Mitchell, D., and Blair, K. (2005). The Psychopath: Emotion and the Brain. Oxford: Blackwell Publishing.

Blanco-Donoso, L. M., García Rubio, C., Moreno Jiménez, B., de la Pinta, M. L. R., Moraleda-Aldea, S., and Garrosa, E. (2017). Intervención breve basada en ACT y mindfulness: estudio piloto con profesionales de enfermería en UCI y urgencias. Int. J. Psychol. Psychol. Ther. 17, $57-73$.

Bloom, P. (2017a). Empathy and its discontents. Trends Cogn. Sci. 21, 24-31. doi: 10.1016 / j.tics.2016.11.004

Bloom, P. (2017b). Against Empathy: The Case for Rational Compassion. New York, NY: Random House.

Campos, B., Shiota, M. N., Keltner, D., Gonzaga, G. C., and Goetz, J. L. (2013) What is shared, what is different? Core relational themes and expressive displays of eight positive emotions. Cogn. Emot. 27, 37-52. doi: 10.1080/02699931.2012. 683852

Cohen, J. (1992). A power primer. Psychological Bulletin 112, 155-159. doi: 10 1037/00332909.112.1.155

Cuff, B. M., Brown, S. J., Taylor, L., and Howat, D. J. (2016). Empathy: a review of the concept. Emot. Rev. 8, 144-153. doi: 10.1177/1754073914558466

Dahl, C. J., Lutz, A., and Davidson, R. J. (2015). Reconstructing and deconstructing the self: cognitive mechanisms in meditation practice. Trends Cogn. Sci. 19, 515-523. doi: 10.1016/j.tics.2015.07.001

De Leersnyder, J., Koval, P., Kuppens, P., and Mesquita, B. (2018). Emotions and concerns: situational evidence for their systematic co-occurrence. Emotion 18:597. doi: $10.1037 / \mathrm{emo} 0000314$

De Waal, F. (2012). The antiquity of empathy. Science 336, 874-876. doi: 10.1126/ science. 1220999

Decety, J., and Lamm, C. (2009). "Empathy versus personal distress-recent evidence from social neuroscience," in The Social Neuroscience of Empathy, eds J. Decety and W. Ickes (Cambridge, MA: MIT Press), 199-213. doi: 10.7551/ mitpress/9780262012973.003.0016

Decety, J., and Yoder, K. J. (2016). Empathy and motivation for justice: cognitive empathy and concern, but not emotional empathy, predict sensitivity to injustice for others. Soc. Neurosci. 11, 1-14. doi: 10.1080/17470919.2015. 1029593

DeSteno, D. (2018). Emotional Success: The Power of Gratitude, Compassion, and Pride. Boston, MA: Houghton Mifflin Harcourt.

Diener, E. (1984). Subjective well-being. Psychol. Bull. 95, 542-575. doi: 10.1037/ 0033-2909.95.3.542

Diener, E. (1998). "Subjective well-being and personality," in Advanced Personality. The Plenum Series in Social/Clinical Psychology, eds D. F. Barone, M. Hersen, and V. B. Van Hasselt (Boston, MA: Springer), doi: 10.1007/978-1-4419-8580$4 \_13$

Diener, E., Oishi, S., and Tay, L. (2018). Advances in subjective well-being research. Nat. Hum. Behav. 2, 253-260. doi: 10.1038/s41562-018-0307-6

Dittmar, H., Bond, R., Hurst, M., and Kasser, T. (2014). The relationship between materialism and personal well-being: a meta-analysis. J. Pers. Soc. Psychol. 107:879. doi: 10.1037/a0037409

Durlak, J., Weissberg, R., Dynmicki, A., Taylor, R., and Schellinger, K. (2011). The impact of enhancing students' social and emotional learning: a meta-analysis of school-based universal interventions. Child Dev. 82, 405-432. doi: 10.1111/j. 1467-8624.2010.01564.x

Eisenberg, A. N. D., Spinrad, T. L., and Sadovsky, A. (2006). Empathy-related responding in children. Handb. Moral Dev. 517:549.

Eisenberg, N. (2010). "Empathy-related responding: links with self-regulation, moral judgment, and moral behavior," in Prosocial Motives, Emotions, and Behavior: The Better Angels of Our Nature, eds M. Mikulincer and P. R. Shaver (Washington, DC: American Psychological Association), 129-148. doi: 10.1037/12061-007

Eisenberg, N., Fabes, R. A., Guthrie, I. K., Murphy, B. C., Maszk, P., Holmgren, R., et al. (1996). The relations of regulation and emotionality to problem behavior in elementary school children. Dev. Psychopathol. 8, 141-162. doi: 10.1017/ S095457940000701X

Emmons, R. A., Froh, J., and Rose, R. (2019). "Gratitude," in Positive Psychological Assessment: A Handbook of Models and Measures, eds M. W. Gallagher and S. J. Lopez (Washington, DC: American Psychological Association), 317-332. doi: $10.1037 / 0000138-020$

Emmons, R. A., and McCullough, M. E. (2004). The Psychology of Gratitude. Oxford: Oxford University Press, doi: 10.1093/acprof:oso/9780195150100.003. 0001

Faul, F., Erdfelder, E., Buchner, A., and Lang, A. G. (2009). Statistical power analyses using $\mathrm{G}^{*}$ Power 3.1: tests for correlation and regression analyses. Behav. Res. Methods 41, 1149-1160. doi: 10.3758/BRM.41.4.1149

Forgas, J. P., and Baumeister, R. F. (2018). "The social psychology of living well: historical, social and cultural perspectives," in The Social Psychology of Living Well, eds J. P. Forgas and R. F. Baumeister (London: Routledge), 1-18. doi: 10.4324/9781351189712

Fredrickson, B. L. (2004). The broaden-and-build theory of positive emotions. Philos. Trans. R. Soc. Lond. Ser. B Biol. Sci. 359, 1367-1377. doi: 10.1098/rstb. 2004.1512

Grouzet, F. M. E., Kasser, T., Ahuvia, A., Fernandez-Dols, J. M., Kim, Y., Lau, S., et al. (2005). The structure of goal contents across 15 cultures. J. Pers. Soc. Psychol. 89, 800-816. doi: 10.1037/0022-3514.89.5.800

Grühn, D., Rebucal, K., Diehl, M., Lumley, M., and Labouvie-Vief, G. (2008). Empathy across the adult lifespan: longitudinal and experience-sampling findings. Emotion 8:753. doi: 10.1037/a0014123

Haidt, J. (2003). "Elevation and the positive psychology of morality," in Flourishing: Positive Psychology and the Life Well-Lived, eds C. L. M. Keyes and J. Haidt (Washington, D.C: American Psychological Association), 275-289. doi: 10. 1037/10594-012

Hayes, A. F. (2017). Introduction to Mediation, Moderation, and Conditional Process Analysis: A Regression-Based Approach. New York, NY: Guilford Publications.

Hayes, A. F. (2018). Partial, conditional, and moderated moderated mediation: quantification, inference, and interpretation. Commun. Monogr. 85, 4-40. doi: 10.1080/03637751.2017.1352100

Hayes, L., and Ciarrochi, J. (2015). The Thriving Adolescent: Using Acceptance and Commitment Therapy and Positive Psychology to Help Young People Manage Emotions, Achieve Goals, and Build Positive Relationships. Oakland, CA: Context Press.

Hope, N. H., Milyavskaya, M., Holding, A. C., and Koestner, R. (2016). The humble path to progress: Goal-specific aspirational content predicts goal progress and goal vitality. Pers. Indiv. Differ. 90, 99-107. doi: 10.1016/j.paid.2015.10.038 0191-8869

Jebb, A. T., Morrison, M., Tay, L., and Diener, E. (2020). Subjective well-being around the world: trends and predictors across the life span. Psychol. Sci. 31, 293-305.

Jolliffe, D., and Farrington, D. P. (2006). Development and validation of the Basic Empathy Scale. J. Adolesc. 29, 589-611. doi: 10.1016/j.adolescence.2005.08.010 
Kahneman, D., and Riis, J. (2005). Living, and thinking about it: two perspectives on life. Sci. Well Being 1, 285-304. doi: 10.1093/acprof:oso/9780198567523.003. 0011

Kasser, T., and Ryan, R. M. (1993). The dark side of the American dream: correlates of intrinsicand extrinsicgoals. J. Pers. Soc. Psychol. 65, 410-422. doi: 10.1037/ /0022-3514.65.2.410

Kasser, T., and Ryan, R. M. (1996). Further examining the American dream: differential correlates of intrinsic and extrinsic goals. Pers. Soc. Psychol. Bull. 22, 280-287. doi: 10.1177/0146167296223006

Lachmann, B., Sindermann, C., Sariyska, R. Y., Luo, R., Melchers, M. C., Becker, B., et al. (2018). The role of empathy and life satisfaction in internet and smartphone use disorder. Front. Psychol. 9:398. doi: 10.3389/fpsyg.2018.00398

Leary, M. R., and Baumeister, R. F. (2017). "The need to belong: desire for interpersonal attachments as a fundamental human motivation," in Interpersonal Development, (London: Routledge), 57-89. doi: 10.1037/00332909.117.3.497

Lekes, N., Gingras, I., Philippe, F. L., Koestner, R., and Fang, J. (2010). Parental autonomy-support, intrinsic life goals, and well-being among adolescents in China and North America. J. Youth Adolesc. 39, 858-869. doi: 10.1007/s10964009-9451-7

Ma, L. K., Tunney, R. J., and Ferguson, E. (2017). Does gratitude enhance prosociality: a meta-analytic review. Psychol. Bull. 143:601. doi: 10.1037/ bul0000103

Martela, F., Bradshaw, E. L., and Ryan, R. M. (2019). Expanding the map of intrinsic and extrinsic aspirations using network analysis and multidimensional scaling: examining four new aspirations. Front. Psychol. 10:2174. doi: 10.3389/fpsyg. 2019.02174

Martela, F., and Ryan, R. M. (2016). The benefits of benevolence: basic psychological needs, beneficence, and the enhancement of well-being. J. Pers. 84, 750-764. doi: 10.1111/jopy.12215

McCullough, M. E., Emmons, R. A., and Tsang, J. A. (2002). The grateful disposition: a conceptual and empirical topography. J. Pers. Soc. Psychol. 82:112. doi: 10.1037/0022-3514.82.1.112

McCullough, M. E., Kilpatrick, S. D., Emmons, R. A., and Larson, D. B. (2001). Is gratitude a moral affect? Psychol. Bull. 127:249. doi: 10.1037//0033-2909.127.2. 249

Mesquita, B., De Leersnyder, J., and Boiger, M. (2016). “The cultural psychology of emotion," in Handbook of Emotions, 4th Edn, eds L. F. Barrett, M. Lewis, and J. M. Haviland-Jones (New York, NY: The Guilford Press), 393-411. doi: 10.1016/j.copsyc.2015.09.015

Mitsopoulou, E., and Giovazolias, T. (2015). Personality traits, empathy and bullying behavior: a meta-analytic approach. Aggress. Violent Behav. 21, 61-72. doi: 10.1016/j.avb.2015.01.007

Morelli, S. A., Lieberman, M. D., and Zaki, J. (2015). The emerging study of positive empathy. Soc. Pers. Psychol. Compass 9, 57-68.

Nishimura, T., and Suzuki, T. (2016). Aspirations and life satisfaction in Japan: the big five personality makes clear. Pers. Indiv. Differ. 97, 300-305. doi: 10.1016/j. paid.2016.02.070

Oros, L. B. (2014). A new questionnaire to assess positive emotions in children. Ann. Psychol. 30, 522-529. doi: 10.6018/analesps.30.2.158361

Post, S. G. (2005). Altruism, happiness, and health: it's good to be good. Int. J. Behav. Med. 12, 66-77. doi: 10.1207/s15327558ijbm1202_4

Preacher, K. J., and Hayes, A. F. (2008). Asymptotic and resampling strategies for assessing and comparing indirect effects in multiple mediator models. Behav. Res. Methods 40, 879-891. doi: 10.3758/brm.40.3.879

Richard, R. D., Bond, C. F. Jr., and Stokes-Zoota, J. J. (2003). One hundred years of social psychology quantitatively described. Rev. Gen. Psychol. 7, 331-363. doi: 10.1037/1089-2680.7.4.331

Robustelli, B. L., and Whisman, M. A. (2018). Gratitude and life satisfaction in the United States and Japan. J. Happiness Stud. 19, 41-55. doi: 10.1007/s10902-0169802-5

Romero, E., Gómez-Fraguela, J. A., and Villar, P. (2012). Life aspirations, personality traits and subjective well-being in a Spanish sample. Eur. J. Pers. 26, 45-55. doi: 10.1002/per.815

Ryan, R. M., and Deci, E. L. (2000). Intrinsic and extrinsic motivations: classic definitions and new directions. Contemp. Educ. Psychol. 25, 54-67. doi: 10.1006/ ceps. 1999.1020
Ryan, R. M., and Deci, E. L. (2017). Self-Determination Theory: Basic Psychological Needs in Motivation, Development, and Wellness. New York, NY: Guilford Publications.

Seligman, M. E., Railton, P., Baumeister, R. F., and Sripada, C. (2013). Navigating into the future or driven by the past. Perspect. Psychol. Sci. 8, 119-141. doi: $10.1177 / 1745691612474317$

Seligson, J. L., Huebner, E. S., and Valois, R. F. (2003). Preliminary validation of the brief multidimensional students' life satisfaction scale (BMSLSS). Soc. Indic. Res. 61, 121-145. doi: 10.1007/s12187-014-9295-x

Siedlecki, K. L., Salthouse, T. A., Oishi, S., and Jeswani, S. (2014). The relationship between social support and subjective well-being across age. Soc. Indic. Res. 117, 561-576. doi: 10.1007/s11205-013-0361-4

Soto, C. M., and Muchotrigo, M. P. G. (2015). Validación estructural de la escala básica de empatía (Basic Empathy Scale) modificada en adolescentes: un estudio preliminar. Revist. Colomb. Psicol. 24, 261-270. doi: 10.15446/rcp.v24n2. 42514

Steger, M., Frazier, P., Oishi, S., and Kaler, M. (2006). The meaning in life questionnaire: assessing the presence of and search for meaning in life. J. Counsel. Psychol. 53, 80-93. doi: 10.1037/0022-0167.53.1.80

Stellar, J. E., Gordon, A. M., Piff, P. K., Cordaro, D., Anderson, C. L., Bai, Y., et al. (2017). Self-transcendent emotions and their social functions: compassion, gratitude, and awe bind us to others through prosociality. Emot. Rev. 9, 200-207. doi: 10.1177/1754073916684557

Stern, J. A., Botdorf, M., Cassidy, J., and Riggins, T. (2019). Empathic responding and hippocampal Vol. in young children. Dev. Psychol. 55, 1908-1920. doi: 10.1037/dev0000684

Unanue, W., Dittmar, H., Vignoles, V. L., and Vansteenkiste, M. (2014). Materialism and well-being in the UK and Chile: basic need satisfaction and basic need frustration as underlying psychological processes. Eur. J. Pers. 28, 569-585. doi: 10.1002/per.1954

Unanue, W., Mella, M. E. G., Cortez, D. A., Bravo, D., Araya-Véliz, C., Unanue, J., et al. (2019). The reciprocal relationship between gratitude and life satisfaction: evidence from two longitudinal field studies. Front. Psychol. 10:2480. doi: 10. 3389/fpsyg.2019.02480

Vachon, D. D., Lynam, D. R., and Johnson, J. A. (2014). The (non) relation between empathy and aggression: surprising results from a meta-analysis. Psychol. Bull. 140:751. doi: 10.1037/a0035236

Van Cappellen, P., Toth-Gauthier, M., Saroglou, V., and Fredrickson, B. L. (2016). Religion and well-being: the mediating role of positive emotions. J. Happiness Stud. 17, 485-505. doi: 10.1007/s10902-014-9605-5

Van Doesum, N. J., Karremans, J. C., Fikke, R. C., de Lange, M. A., and Van Lange, P. A. (2018). Social mindfulness in the real world: the physical presence of others induces other-regarding motivation. Soc. Influence 13, 209-222. doi: 10.1080/15534510.2018.1544589

Wood, A. M., Joseph, S., and Maltby, J. (2008). Gratitude uniquely predicts satisfaction with life: incremental validity above the domains and facets of the five factor model. Pers. Indiv. Differ. 45, 49-54. doi: 10.1016/j.paid.2008. 02.019

Yu, H., Gao, X., Zhou, Y., and Zhou, X. (2018). Decomposing gratitude: representation and integration of cognitive antecedents of gratitude in the brain. J. Neurosci. 38, 4886-4898. doi: 10.1523/JNEUROSCI.2944-17. 2018

Zaki, J. (2020). The War for Kindness: Building Empathy in a Fractured World. Portland: Broadway Books.

Conflict of Interest: The authors declare that the research was conducted in the absence of any commercial or financial relationships that could be construed as a potential conflict of interest.

Copyright (c) 2020 Oriol, Unanue, Miranda, Amutio and Bazán. This is an openaccess article distributed under the terms of the Creative Commons Attribution License (CC BY). The use, distribution or reproduction in other forums is permitted, provided the original author(s) and the copyright owner(s) are credited and that the original publication in this journal is cited, in accordance with accepted academic practice. No use, distribution or reproduction is permitted which does not comply with these terms. 